ORIGINAL RESEARCH ARTICLE

\title{
Disparities in Abortion Experience and Access to Safe Abortion Services in Ghana: Evidence from a Retrospective Survey
}

\author{
John K. Ganle ${ }^{*}$, Bernard Obeng ${ }^{2}$, Joseph Y. Yeboah ${ }^{3}$, Eva Tagoe-Darko ${ }^{3}$ and Charlotte M. \\ Mensah $^{3}$
}

Department of Population, Family and Reproductive Health, School of Public health, University of Ghana, Legon, Accra, Ghana $^{1}$; Department of Sociology \& Social Work, Kwame Nkrumah University of Science \& Technology, Kumasi, Ghana ${ }^{2}$; Population, Health and Gender Research Group, Department of Geography \& Rural Development, Kwame Nkrumah University of Science \& Technology, Kumasi, Ghana ${ }^{3}$

*For Correspondence: Email: zabzugu.gan@gmail.com; Phone: +233249957505

\begin{abstract}
In Ghana, abortion mortality constitutes $11 \%$ of maternal mortality. Empirical studies on possible disparities in abortion experience and access to safe abortion services are however lacking. Based on a retrospective survey of 1,370 women aged 15-49 years in two districts in Ghana, this paper examines disparities in women's experiences of abortion and access to safe abortion care. Disparities in rates of abortion experience and access to safe abortion care were assessed using absolute (the difference in rates between groups), relative (the ratio of rates between selected and reference groups), and mean measures. Results suggest that $24 \%$ of women had at least one abortion in the five years preceding the survey. However, large gradients of socio-spatial disparities in abortion experience exist. The majority of abortions were also potentially unsafe: $53 \%$ of abortions occurred outside of any healthcare facility. Women themselves and medical doctors, respectively, performed $57 \%$ and $4 \%$ of all abortions. The majority of women also felt they could not get safe abortion even if they wanted one. Together, these results highlight the need for concerted multi-sectorial strategies, including legislative reform and provision of family planning services, to help transition from unsafe to safe abortions. (Afr J Reprod Health 2016; 20[2]: 43-52).
\end{abstract}

Keywords: Disparities, Unsafe abortion, Contraceptive use, Family planning, Abortion law, Ghana.

\section{Résumé}

Au Ghana, la mortalité causée par l'avortement constitue $11 \%$ de la mortalité maternelle. Des études empiriques sur les disparités possibles dans l'expérience de l'avortement et l'accès aux services d'avortement sans risque font cependant défaut. Basé sur une étude rétrospective de 1370 femmes âgées de 15-49 ans dans deux districts au Ghana, cet article étudie les disparités dans les expériences de l'avortement et l'accès des femmes à l'avortement médicalisé. Les disparités des taux d'expérience de l'avortement et de l'accès aux services d'avortement médicalisé ont été évalués à l'aide des mesures absolues (la différence de taux entre les groupes), relatives (le rapport des taux entre les groupes de référence sélectionnés et) et moyennes. Les résultats suggèrent que $24 \%$ des femmes ont eu au moins un avortement au cours des cinq années précédant l'enquête. Cependant, d'importants gradients de disparités socio-spatiales dans l'expérience de l'avortement existent. La majorité des avortements étaient également potentiellement dangereux: 53\% des avortements ont eu lieu en dehors d'un établissement de santé. Les femmes elles-mêmes et les médecins, ont réalisées $57 \%$ et $4 \%$ de tous les avortements respectivement.. La majorité des femmes a également estimé qu'elles ne pouvaient pas obtenir un avortement sans risque, même si elles en voulaient un. Ensemble, ces résultats mettent en évidence la nécessité de stratégies multisectorielles concertées, y compris la réforme législative et la fourniture de services de planification familiale, pour aider à la transition de l'avortement dangereux vers l'avortement sans danger. (Afr J Reprod Health 2016; 20[2]: 43-52).

Mots-clés: disparités, avortement à risque, utilisation de la contraception, planification familiale, loi sur l'avortement, Ghana

\section{Introduction}

Every year, some 42 million women worldwide with unintended pregnancies choose to end their pregnancy through abortion ${ }^{1}$. More than half $(22$ million) of these women however use unsafe procedures to end their pregnancy'. 'Unsafe abortion' is defined as a procedure for terminating a pregnancy carried out either by persons lacking the necessary skills or in an environment that does not conform to minimal medical standards, or both $^{2}$. Although the overall global abortion rate has declined, the proportion of unsafe abortion is on the rise, especially in low-income countries where $55 \%$ of abortions are unsafe compared to only $3 \%$ in high-income countries ${ }^{1,3,4,5}$. 
In Ghana, abortion, especially unsafe abortion, remains one of the major public health challenges. Health facility level data suggest that more than one in ten maternal deaths $(11 \%)$ in Ghana is attributable to unsafe abortion ${ }^{6-9}$. Recent anecdotal data suggest that in some leading hospitals in the country, unsafe abortion is the second leading cause of maternal mortality, accounting for 25$30 \%{ }^{10}$. Indeed, Ghana's Reproductive Health Strategic Plan (2007-2011) whose objective was to reduce maternal morbidity and mortality acknowledged that unsafe abortion was impeding the country's effort at achieving the MDG 5 target of reducing maternal mortality by $75 \%$ by $2015^{11}$.

Despite the relatively high proportion of maternal mortality that abortion contributes to in Ghana, abortion is largely a taboo subject, with unsafe abortion remaining one of the most neglected topics of health ${ }^{7,12}$. This silence is compounded by the fact that induced abortion is illegal and a criminal offense, regulated by Act 29, Section 58 of Ghana's Criminal Code of $1960^{13}$. An amendment to this law (PNDCL 102) in 1985 took a rather limited liberal view of abortion, specifically prescribing certain circumstances under which legal abortion might be permitted. These conditions include pregnancies that result from rape, incest, and 'defilement of a female idiot'; where there is high risk that the child would suffer serious deformity if born; and if the pregnancy threatens the physical or mental health of the $\operatorname{woman}^{11,13}$. This notwithstanding, integration of safe abortion care into Ghana's reproductive health policy has not widely occurred, and the general silence around abortion makes it not only hard to know the magnitude of the problem, but also even more difficult to undertake appropriate policy reforms and changes necessary for redressing the unsafe abortion problem and saving women's lives ${ }^{13}$. In addition, it is not clear whether there are differences in abortion prevalence among different groups of women. The purpose of this study was therefore to examine the occurrence of abortion among women of reproductive age as well as women's ability to access safe abortion services in Ghana.

\section{Methods}

\section{The survey design}

The survey was designed as a descriptive retrospective five-year (2009-2013) survey of 1,370 individual women of reproductive age (1549 years) in the Bosomtwi and Central Gonja districts of the Ashanti region and Northern region of Ghana respectively. The survey formed part of a larger, original multi-method study that was conducted between November 2011 and May 2015 in the Bosomtwe and Central Gonja districts of Ghana to examine the effects of Ghana's user-fee exemption policy on women's maternity care seeking experience, equity of access, and barriers to accessibility and utilisation of reproductive, maternal and newborn healthcare services. A number of articles - based on both qualitative and quantitative analysis of data generated from this larger study - have already been published ${ }^{14-19}$. In this paper, the focus is on reporting findings from a component of the survey, which examined women's experiences of abortion as well as accessibility to safe abortion services.

The survey component of the study was conducted in two phases, and employed a twostage sampling procedure. In phase I, a short household survey questionnaire was administered to 850 randomly selected households from a total of six randomly selected communities in the two study districts. The purpose of this phase I survey was to identify women of reproductive age (i.e. 1549 years) who could form the sample for the actual survey in Phase II. Out of the 850 households sampled in Phase I, 842 households completed the short household questionnaire, giving a 99\% response rate. A total of 1,390 women were identified from the 842 households as eligible for individual interview in Phase II.

In Phase II, a detailed individual questionnaire was administered to all the 1,390 eligible individual women identified in Phase I. Out of the 1,390 women, interviews were completed for 1,370 . The response rate was $98.6 \%$. The main objective in Phase II was to collect 
Ganle et al.

information on women's experience of abortion in the five years preceding the survey, the places where the abortion was performed, the persons who performed the abortion, women's perceptions of their ability to access and use abortion care if they wanted one.

\section{Questionnaire design and data collection}

Questionnaires were the data collection instruments. The questionnaires were first prepared in English, and translated into three local interview languages: Akan, Dagbani, and Gonja. Following from this, the translated questionnaires were pretested to detect any problems in the translations or the flow of the questioning, as well as to gauge the length of time required for interviews. Ten (10) female interviewers -5 from each of the two study districts, and with proficiency in the relevant local language - were engaged to do the pretest and main interviewing. All the interviewers were trained for three days. The training was followed with the actual pretest interviewing, which took a day to complete. Each of the 10 interviewers interviewed 3 women using the relevant interview language. Where necessary, the pretest results were used to modify the survey instrument. This was followed up with the main survey, which took a total of three months.

\section{Variables and measurement}

To assess disparities in women's experiences of abortion and access to safe abortion care in the five years preceding the survey, we followed a threestep procedure. The procedure involved (i) definition of the indicators of abortion care; (ii) classification of the population into different strata by socio-spatial variable stratifiers; and (iii) assessing abortion experiences and differences in access levels across the variable stratifiers.

\section{Indicators}

The first step involved definition of the indicators of abortion experiences and access to abortion care whose distributions are to be measured. These indicators included (i) a woman's experience of having an abortion in the five years preceding the survey; (ii) place where abortion was undertaken;
Disparities in Abortion Experience

(iii) person performing the abortion; (iv) ability to access abortion care if need be; and (v) knowledge of places to get abortion care if needed.

\section{The socio-spatial variable stratifiers}

In the second step, we defined and used variable stratifiers to classify women. These variables were classified into two broad categories: sociodemographic and spatial variables. The sociodemographic variables were (i) women's level of education; (ii) age; (iii) wealth quintiles; (iv) marital status; (v) religion; (vi) ethnicity; and (vii) number of living children. The spatial variables were (i) place of residence (urban/rural), and (ii) geographical district of residence.

\section{Data processing}

All completed survey questionnaires were retrieved for data processing. Data processing, including training of 3 data entry personnel, consisted of office editing, coding of open-ended questions, data entry, and resolving inconsistencies. The data were processed and entered on microcomputers using IBM SPSS Statistics software version 20.

\section{Data analysis}

Disparities in abortion experience and access to safe abortion services were assessed through comparisons of rates across the different variable stratifiers. Rates of abortion experience and access to abortion care for different women were assessed using absolute (the difference in rates between groups), relative (the ratio of rates between selected and reference groups), and mean measures. All the data analyses were performed using the IBM SPSS Statistics data analysis software package (version 20).

\section{Ethics}

Ethical clearance for the study was obtained from the University of Oxford Social Sciences and Humanities Inter-divisional Research Ethics Committee (Ref No. SSD/CUREC1/11-051), and the Ghana Health Service Ethical Review Committee (Protocol ID No. GHS-ERC 18/11/11). In addition, informed written and verbal consents were obtained from all research participants. 
Ganle et al.

Table 1: Socio-Demographic Characteristics of Respondents $(n=1,370)$

\begin{tabular}{|c|c|}
\hline Characteristic & Number $(\%)$ \\
\hline \multicolumn{2}{|l|}{ Age } \\
\hline $15-24$ & $441(32.2)$ \\
\hline $25-34$ & $504(36.8)$ \\
\hline $35-44$ & $385(28.1)$ \\
\hline $45+$ & $40(2.9)$ \\
\hline \multicolumn{2}{|l|}{ Marital Status } \\
\hline Never Married & 489 (35.6) \\
\hline Married & $753(54.9)$ \\
\hline Divorced/Separated & $104(7.6)$ \\
\hline Widowed & $26(1.9)$ \\
\hline \multicolumn{2}{|l|}{ Residence } \\
\hline Rural & $591(43.1)$ \\
\hline Urban & 779 (56.9) \\
\hline \multicolumn{2}{|l|}{ District } \\
\hline Bosomtwe & $778(56.8)$ \\
\hline Central Gonja & $592(43.2)$ \\
\hline \multicolumn{2}{|l|}{ Education } \\
\hline None & $353(25.8)$ \\
\hline Primary & $292(21.3)$ \\
\hline Middle/JSS & $542(39.6)$ \\
\hline Secondary+ & $183(13.3)$ \\
\hline \multicolumn{2}{|l|}{ Ethnicity } \\
\hline Akan & $732(53.4)$ \\
\hline Dagomba & $262(19.1)$ \\
\hline Gonja & $303(22.2)$ \\
\hline Other & $73(5.3)$ \\
\hline \multicolumn{2}{|l|}{ Religion } \\
\hline Christian & $720(52.6)$ \\
\hline Moslem & $537(39.2)$ \\
\hline Traditional & $84(6.1)$ \\
\hline Other & $29(2.1)$ \\
\hline \multicolumn{2}{|l|}{ Wealth Quintile } \\
\hline Lowest & $556(40.6)$ \\
\hline Second & $397(29.0)$ \\
\hline Middle & $214(15.6)$ \\
\hline Fourth & $140(10.2)$ \\
\hline Highest & $63(4.6)$ \\
\hline \multicolumn{2}{|c|}{ Number of Living Children } \\
\hline 0 & $423(30.9)$ \\
\hline 1 & $210(15.3)$ \\
\hline $2-3$ & $381(27.8)$ \\
\hline $4+$ & $356(26.0)$ \\
\hline Total & $1,370(100)$ \\
\hline
\end{tabular}

\section{Results}

\section{Characteristics of respondents}

Table 1 illustrates the characteristics of the survey respondents. A considerable percentage of the respondents (26\%) had never been to school, while $21 \%, 40 \%$, and $13 \%$ had, respectively, attended Primary School, Middle/Junior Secondary School,
Disparities in Abortion Experience

and Secondary School or a higher level as their highest level of education. Just over half of the respondents $(57 \%)$ resided in rural areas, while majority (52.6\%) were Christians.

\section{Women's awareness and experience of abortion}

Figure 1 shows women's awareness and experience of abortion in the five years preceding the survey. All respondents $(100 \%)$ had heard about abortion. Majority of the women $(75.5 \%)$ had heard about abortion but did not have an abortion in the five years preceding the survey. However, nearly one in every four women $(24.1 \%)$ had heard about abortion and did have an abortion in the five years preceding the survey.

While the above statistics provide a broad indicator of the prevalence of abortion among women of reproductive age in the two study districts in the five years before the survey, these figures mask the fact that large socio-spatial disparities in abortion experiences exist for different women. Table 2 illustrates the distribution of women who have heard of abortion and had an abortion in the five years preceding the survey by background characteristics. Generally, more women in urban centres (19.9\%) reported having an abortion compared with women in rural areas $(10.4 \%)$. More women in the Bosomtwe district $(20.8 \%)$ also had abortion than in the Central Gonja district (16.3\%). Similarly, the proportion of women who reported having an abortion ranged from a high of $22.6 \%$ among women in the highest wealth quintile to a low of $5.8 \%$ among women in the lowest wealth quintile. The percentage of women reporting having an abortion in the five years preceding the survey generally increases with level of education, while more never married (24.6\%), divorced/separated (16.6\%), and widowed (7.3) women had abortion compared to women currently married (2.1\%).

\section{Place of abortion and person performing abortion}

Knowledge of the places where women went for abortion and the person who performed the procedure are essential for gauging the safety or 
Table 2: Women who had an Abortion in the Five Years Preceding the Survey

\begin{tabular}{|c|c|c|c|}
\hline Characteristic & $\begin{array}{l}\text { Number of Women } \\
\text { Interviewed } n(\%)\end{array}$ & $\begin{array}{l}\text { Women Who Heard } \\
\text { about Abortion and Had } \\
\text { an Induced Abortion } n \\
(\%)\end{array}$ & $\begin{array}{l}\text { Mean Number of } \\
\text { Abortions }\end{array}$ \\
\hline \multicolumn{4}{|l|}{ Age } \\
\hline $15-24$ & $441(32.2)$ & $97(22.0)$ & 1.6 \\
\hline $25-34$ & $504(36.8)$ & 99 (19.7) & 1.5 \\
\hline $35-44$ & $385(28.1)$ & 46 (11.9) & 1.3 \\
\hline $45+$ & $40(2.9)$ & $2(2.8)$ & 1.1 \\
\hline \multicolumn{4}{|l|}{ Marital Status } \\
\hline Never Married & 489 (35.6) & $120(24.6)$ & 1.5 \\
\hline Married & $753(54.9)$ & $16(2.1)$ & 1.3 \\
\hline Divorced/Separated & $104(7.6)$ & $17(16.6)$ & 1.4 \\
\hline Widowed & $26(1.9)$ & $2(7.3)$ & 1.0 \\
\hline \multicolumn{4}{|l|}{ Residence } \\
\hline Rural & $591(43.1)$ & $61(20.8)$ & 1.6 \\
\hline Urban & $779(56.9)$ & $155(19.9)$ & 1.2 \\
\hline \multicolumn{4}{|l|}{ District } \\
\hline Bosomtwe & $778(56.8)$ & $161(20.8)$ & 1.6 \\
\hline Central Gonja & $592(43.2)$ & $73(12.3)$ & 1.2 \\
\hline \multicolumn{4}{|l|}{ Education } \\
\hline None & $353(25.8)$ & $21(6.0)$ & 1.3 \\
\hline Primary & $292(21.3)$ & $42(14.4)$ & 1.4 \\
\hline Middle/JSS & $542(39.6)$ & $104(19.2)$ & 1.6 \\
\hline Secondary+ & $183(13.3)$ & $31(17.0)$ & 1.5 \\
\hline \multicolumn{4}{|l|}{ Ethnicity } \\
\hline Akan & $732(53.4)$ & $163(22.2)$ & 1.6 \\
\hline Dagomba & $262(19.1)$ & $40(15.1)$ & 1.4 \\
\hline Gonja & $303(22.2)$ & $43(14.2)$ & 1.3 \\
\hline Other & $73(5.3)$ & $12(16.5)$ & 1.5 \\
\hline \multicolumn{4}{|l|}{ Religion } \\
\hline Christian & $720(52.6)$ & $152(21.1)$ & 1.6 \\
\hline Moslem & $537(39.2)$ & $87(16.20$ & 1.4 \\
\hline Traditional & $84(6.1)$ & $11(12.6)$ & 1.3 \\
\hline Other & $29(2.1)$ & $4(15.4)$ & 1.4 \\
\hline \multicolumn{4}{|l|}{ Wealth Quintile } \\
\hline Lowest & $556(40.6)$ & $32(5.8)$ & 1.1 \\
\hline Second & $397(29.0)$ & $34(8.5)$ & 1.3 \\
\hline Middle & $214(15.6)$ & $29(13.5)$ & 1.3 \\
\hline Fourth & $140(10.2)$ & $25(18.0)$ & 1.5 \\
\hline Highest & $63(4.6)$ & $14(22.6)$ & 1.6 \\
\hline \multicolumn{4}{|c|}{ Number of Living Children } \\
\hline 0 & $423(30.9)$ & $30(7.1)$ & 1.3 \\
\hline 1 & $210(15.3)$ & $37(17.5)$ & 1.4 \\
\hline $2-3$ & $381(27.8)$ & $79(20.8)$ & 1.5 \\
\hline $4+$ & $356(26.0)$ & $54(15.1)$ & 1.5 \\
\hline
\end{tabular}

otherwise of the abortion. In this study women who reported having an abortion in the five years preceding the survey were asked about the place where the abortion was done and the person who performed the abortion. The results, shown in Figure 2, suggest that majority (53\%) of abortions occurred outside of any health facility setting. A substantial number $(30 \%)$ of abortions however occurred in private hospitals and clinics. Abortions took place less commonly in government hospitals and clinics, and in a private pharmacy or drug store. As regards the person who performed the abortion, women conducted $57 \%$ of all abortions themselves, while a friend/relative and traditional practitioner conducted a combined total of $19 \%$ of abortions (Figure 2). Strikingly, medical doctors conducted only $4 \%$ of all abortions. 
Figure 1: Women's Awareness and Experience of Abortion

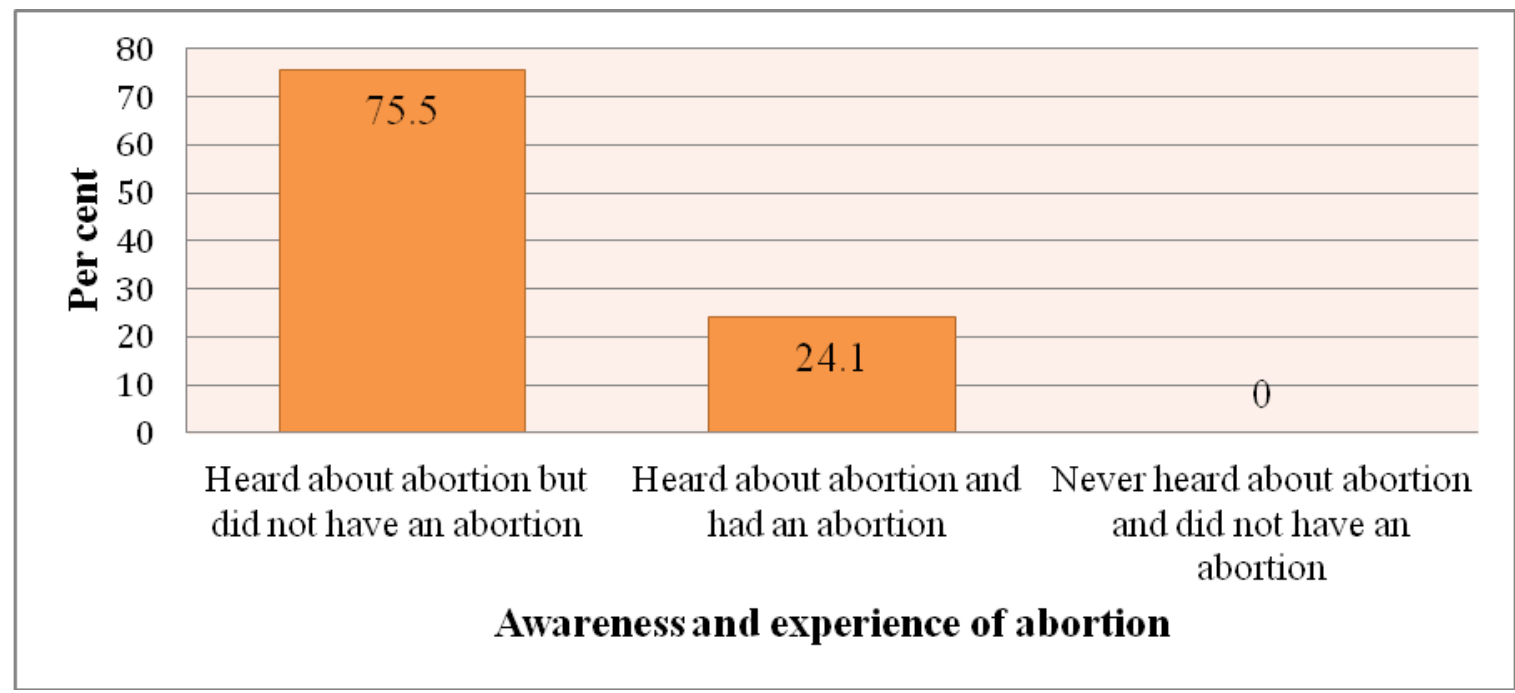

Figure 2: Person Performing the Abortion.

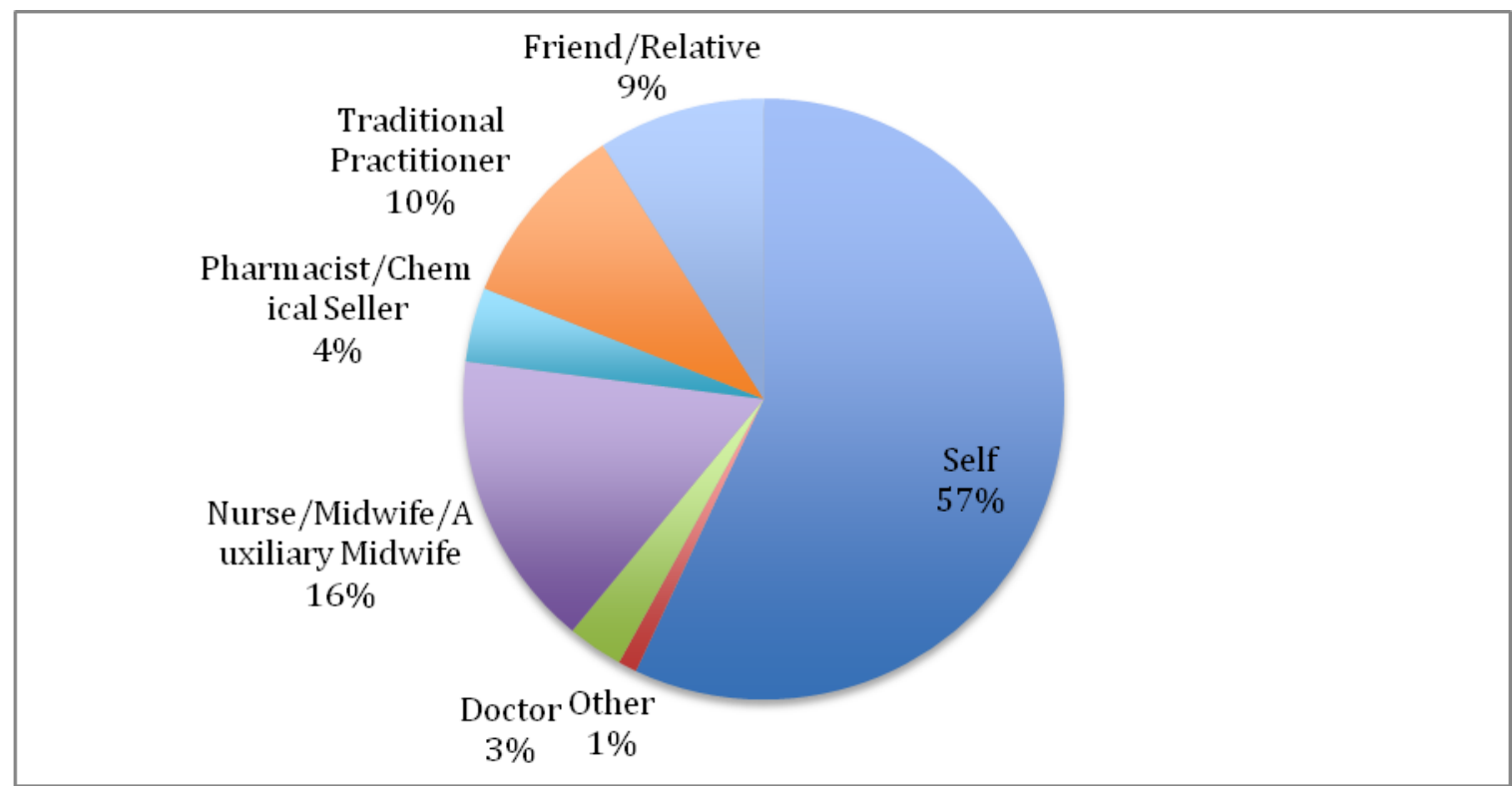

\section{Abortion methods}

In terms of the methods women used to abort their pregnancy, Figure 3 shows the percent distribution of women who had an induced abortion in the five years preceding the survey by method used to terminate the pregnancy.

The most common abortion method is drinking of herbal concoction (40\%). However,
$16 \%$ of women terminated their pregnancy by dilation and curettage, while $12 \%$ of women inserted herbs and other objects and substances into their vagina to end their pregnancy. For some women, taking tablets (6\%) and manual vacuum aspiration (7\%) were the methods used to terminate the pregnancy. Relatively safer but lesser used methods included the use of cytotec (misoprostol) tablets (3\%) and injection (3\%). 
Figure 3: Action Taken to Abort Pregnancy

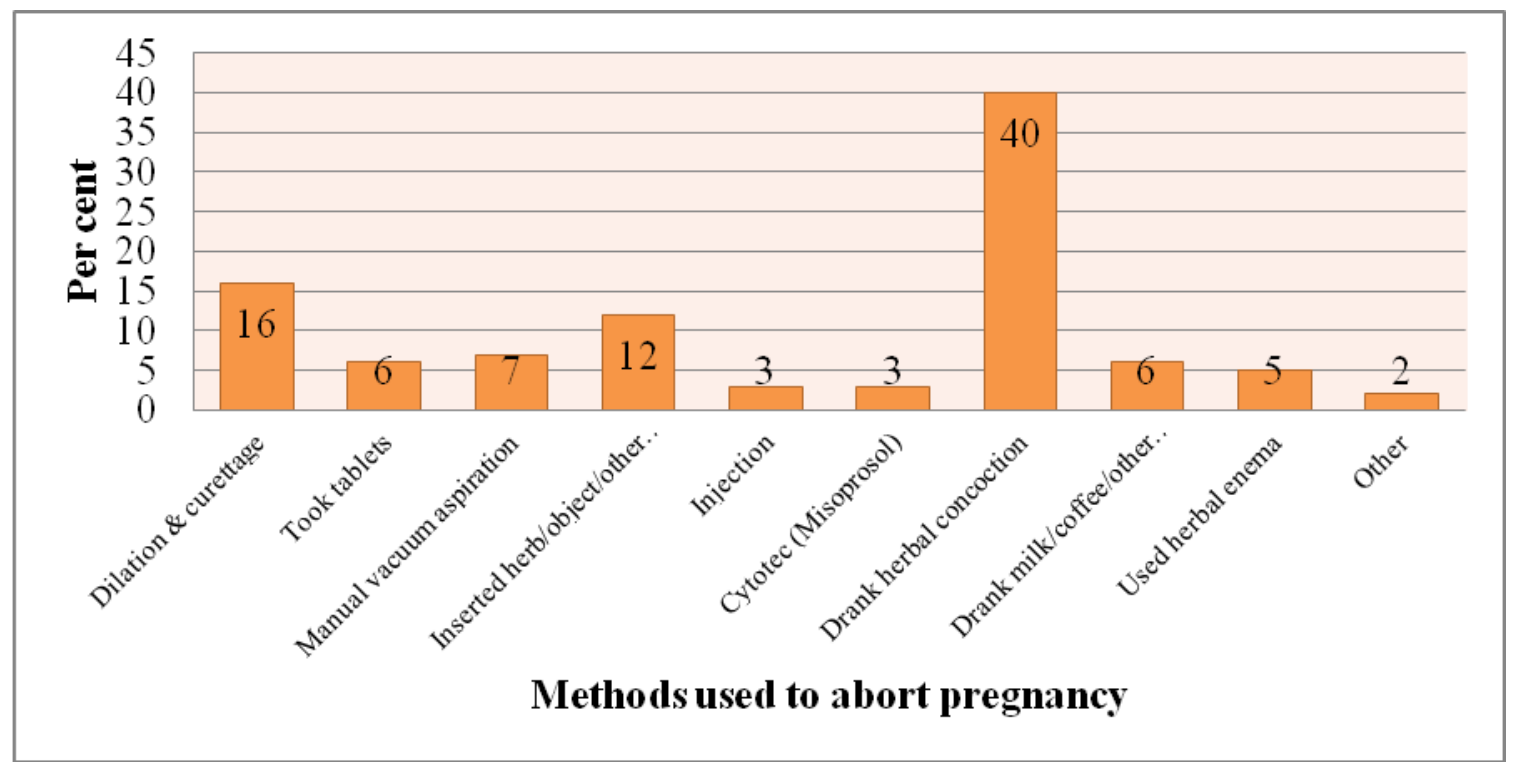

\section{Discussion}

This paper has attempted to assess the occurrence of abortion among women of reproductive age in two districts in Ghana, and the ability of women to access and use safe abortion services. While the method of self-reporting used in collecting data related to women's experiences of abortion and their ability to access abortion services could be a limitation as it can result in the under-reporting of abortion on a small or large scale, results from descriptive statistical analysis showed that all the respondents (100\%) had heard about abortion, with $24 \%$ of respondents or nearly one in every four women reporting aborting at least one pregnancy in the five years preceding the survey. This figure is very consistent with data from Ghana's 2007 Maternal Health Survey ${ }^{20}$. The relatively high percentage of women who aborted their pregnancies in the five years before the survey raises questions about contraceptive use and family planning among the survey respondents. While this study did not assess women's access to family planning and contraceptive services, data from Ghana's 2014 Demographic and Health Survey suggest that $78 \%$ of Ghanaian women are not using any form of contraceptive method ${ }^{21}$. Also, $30 \%$ of women still have unmet need for family planning services $^{21}$. Although the availability and use of modern contraception can never eliminate the need for abortion, improved access to family planning methods and effective contraception use has been shown to greatly reduce the incidence of unwanted pregnancies and unsafe abortion ${ }^{3,7}$. The findings here would therefore suggest the need to address both women's unmet need for family planning as well as the barriers to contraceptive use. This can be achieved by ensuring that healthcare providers and healthcare facilities offer a range of family planning and contraceptive methods and services free-of-charge or at a very moderate fee. Both women and men must also be engaged (e.g. through couple counselling) on issues of family planning and contraceptive options so as to help them accept, identify and obtain the methods that work best for them. Addressing women's concerns about side effects of family planning and contraceptive use might also contribute to increased and improved contraceptive use. Further analysis of data however indicated that large gradients of disparities in abortion experience exist between different women groups. For example whereas only $10.4 \%$ of rural women reported aborting at least one pregnancy in the five years preceding the survey, $19.9 \%$ of women in urban centres did. Similarly, only $6 \%$ of women in the lowest wealth quintile reported having an abortion compared to $23 \%$ of women in the highest wealth 
quintile. Also, whereas only $6 \%$ of women with no formal education reported aborting at least one pregnancy in the five years preceding the survey, $19 \%$ and $17 \%$ of women with middle and secondary school education, respectively, reported having an abortion during the same period.

It is difficult to explain the observed disparities in women's experiences of abortion from this study. More qualitative research is required to explore why, for example, more never married, divorced/separated, and widowed women than women currently married, experienced abortion in the five years preceding the survey. However, based on previous literature and the socio-economic and political organisation of the study districts, a number of factors could potentially explain some of these disparities. For instance, maternal education is positively associated with access and use of many of the elements of reproductive health services including abortion $^{22,23}$. Influences of maternal education on abortion can be affected in several ways, including empowering women to be able to leverage decision-making power regarding reproductive choices such as contraceptive use and access to abortion services ${ }^{24}$. This could potentially explain why more women with higher levels of education reported aborting their pregnancies than women with no or limited education. Also, wealth-related disparities could be explained by such factors as poverty, high financial costs of abortion services, and other opportunity and social costs. This might explain the rich-poor gap in the occurrence of abortion among the survey respondents. Similarly, spatial disparities in the occurrence of abortion between urban and rural women could partly be linked to a number of supply-side and demand-side factors, whereby there is urban-bias in the availability of, quality of, and ease of access to, abortion services. This is more likely to be so in the study districts where there is marked ruralurban disparity in general healthcare provisioning ${ }^{25}$. It could also partly be because there is a high concentration of the better-educated and economically empowered women in urban areas than in rural areas. Both education and wealth could contribute to enabling more urban women than rural women, not only to make decisions in favour of terminating an unwanted pregnancy, but also to take concrete steps to access abortion services.

Apart from disparities in women's experiences of abortion, results also revealed that majority (53\%) of abortions occurred outside of any healthcare facility. Women themselves conducted $57 \%$ of all abortions, with medical doctors performing only $4 \%$ of all abortions. Similarly, the majority of women either drank herbal concoctions or inserted other herbs/substances into their vagina to terminate their pregnancy. That many abortions occurred at home and without the supervision of trained healthcare professionals, and that many women drank herbal concoctions to end their pregnancy suggest that the majority of abortions were potentially unsafe. This is because these women were unlikely to have been properly equipped with the necessary skills to conduct abortions by themselves neither were their homes likely to conform to the minimal medical standards that are required. As the WHO has argued, unsafe abortion occurs when the procedure for terminating a pregnancy is carried out either by persons lacking the necessary skills or in an environment that does not conform to minimal medical standards or both ${ }^{1}$.

A number of factors including negative cultural and religious attitudes towards induced abortion, and limited availability of legally safe abortion services in healthcare facilities could potentially explain why many abortions occurred at home and were performed by unqualified persons and through relatively unsafe abortion procedures. As mentioned earlier, induced abortion is still largely criminalised in Ghana except in a limited number of situations such as rape and incest ${ }^{12,13}$. This restriction has often been interpreted to mean that induced abortion is illegal in Ghana. The idea that induced abortion is illegal in Ghana has meant that integration of safe abortion services into Ghana's healthcare delivery system has not widely occurred. As previous research in Ghana has demonstrated, women and many healthcare providers are not even familiar with opportunities provided under the law to terminate unwanted pregnancies safely, and policymakers do not regularly provide and disseminate clear guidelines and procedures for abortion and post-abortion care $^{12}$. Ghana's relatively restrictive abortion law 
could therefore drive many women towards illegal and unsafe abortion, for access to safe abortion is often mediated by women's awareness of the law that abortion is legal. Indeed, previous studies have shown that unsafe abortion and related mortality are both highest in countries with narrow grounds for legal abortion ${ }^{2,26}$.

Of course legalisation of abortion alone might not be a sufficient step toward eliminating unsafe abortion. Even when abortion laws are more liberal, adverse socio-economic, cultural, and religious factors may prevent women from seeking services. Nevertheless, as one of the few countries in Sub-Saharan Africa where abortion is legal on limited grounds, Ghana is particularly well positioned to take steps to liberalise its abortion laws and broaden the basis for legal abortion so as to remedy the problem of unsafe abortion. Indeed, access to safe, legal abortion must now be seen as a fundamental right of women, irrespective of where they live. Moreover, making abortion legal, safe, and accessible does not appreciably increase demand as shown by some studies ${ }^{4,5,22}$. Instead, the principal effect is shifting previously clandestine, unsafe procedures to legal and safe ones ${ }^{27}$. Because enabling abortion legislation is necessary but not sufficient, legalisation must come with the development of programmes to increase both local community awareness and access to safe abortion. Legalisation must also include the integration and institutionalisation of abortion and post-abortion care for incomplete abortion and early and appropriate treatment of more severe complications of abortion. As previous studies in Ghana and Zambia have shown, the lack of strong service delivery systems that integrate abortion and postabortion care is the major reason why women in these countries still suffer complications of unsafe abortion $^{2,12}$. In addition, there is also the need for improvement in women's education in the study districts, up to at least secondary level, in order to bridge the equity gap and improve access to essential family planning, contraceptive and safe abortion services.

\section{Conclusion}

The findings from this descriptive survey in two districts in Ghana have shown that several women experience abortions that are potentially unsafe.
This suggests the need for an open debate and policy reform in our study districts to address the challenge of unsafe abortion. In particular, a concerted multi-sectorial strategy that not only includes legislative reform to make safe abortion legal but also that involves aggressive large scale public education effort that takes into account the sensitive, often secretive, nature of abortion and raises awareness about Ghana's abortion law is needed if the proportion of abortions that are carried out safely is to be increased and the maternal health-related MDGs attained. In addition, strategies to promote improved access to effective modern family planning methods and contraception are needed to help reduce the incidence of unwanted pregnancies.

\section{Acknowledgement}

This research received funding from a Wellcome Trust Doctoral Fellowship programme as part of a Wellcome Trust Enhancement Award (Number 087285) to the Ethox Centre, Nuffield Department of Population Health, University of Oxford.

\section{Contribution of Authors}

John K. Ganle conceived and designed the study. John K. Ganle, Bernard Obeng and Joseph Y. Yeboah collected data. John K. Ganle and Eva Tagoe-Darko analysed the data. John K. Ganle and Charlotte M. Mensah prepared the first draft of the manuscript. All authors reviewed the draft and approved the manuscript.

\section{References}

1. World Health Organization: Safe Abortion: Technical and Policy Guidance for Health Systems (Second Edition). Geneva: World Health Organization; 2012.

2. Coast E and Murray FS: "These things are dangerous": Understanding induced abortion trajectories in urban Zambia. Social Science \& Medicine, 2016, 153:201-209.

3. Haddad LB \& Nour NM: Unsafe abortion: Unnecessary maternal mortality. Reviews in Obstetrics \& Gynecology, 2009, 2(2): 122-126.

4. Rasch V, Sørensen HP, Wang RA, Tibazarwa F \& Jäger KA: Unsafe abortion in rural Tanzania - the use of traditional medicine from a patient and a provider perspective. BMC Pregnancy and Childbirth, 2014, 14:419

5. Norris A, Harrington JB, Grossman D, Hemed M \& 
Ganle et al.

Hindin JM: Abortion experiences among Zanzibari women: a chain-referral sampling study. Reproductive Health, 2016, 13:23.

6. Ghana Health Services: Reproductive and Child Health Annual Programme of Work. Ghana Health Services, Ghana, Reproductive and Child Health; 2006.

7. Baiden F, Amponsa-Achiano K, Oduro A, Mensah T, Baiden R \& Hodgson A: Unmet need for essential obstetric services in a rural district in northern Ghana: complications of unsafe abortions remains a major cause of mortality. Journal of Royal Institute of Public Health, 2006, 120(5): 421-426.

8. Abor PA, Abekah-Nkrumah G \& Sakyi K: The socioeconomic determinants of maternal health care utilization in Ghana. International Journal of Social Economics, 2011, 38(7): 628-648.

9. Asamoah OB, Moussa KM, Stafstrom M \& Musinguzi G: Distribution of causes of maternal mortality among different socio-demographic groups in Ghana: a descriptive study. BMC Public Health, 2011, 11(159): 1-10.

10. Daily Guide, 'Abortion Cases Rise', August 21, 2012.

11. Ministry of Health: National Consultative Meeting on the Reduction of Maternal Mortality in Ghana: Partnership for Action. Synthesis, Ministry of Health, Ghana, Policy Planning Monitoring and Evaluation Department; 2008.

12. Oduro YA \& Ostin ANM: "Abortion-It Is My Own Body": Women's Narratives About Influences on Their Abortion Decisions in Ghana. Health Care for Women International, 2014, 35:918-936.

13. Morhee RAS \& Morhee ESK: Overview of the law and availability of abortion services in Ghana. Ghana Medical Journal, 2006, 40(3): 80-86.

14. Ganle JK, Parker M, Fitpatrick R, \& Otupiri E: Free maternity care and equity of access to maternal health services in Ghana: a descriptive study. International Journal for Equity in Health, 2014, 13:89.

15. Ganle JK, Parker M, Fitpatrick R \& Otupiri E: A qualitative study of health system barriers to accessibility and utilization of maternal and newborn healthcare services in Ghana after user-fee abolition. BMC Pregnancy and Childbirth, 2014, 14:425.

16. Ganle JK: Ethnic disparities in utilisation of maternal healthcare services in Ghana: Evidence from the 2007 Ghana maternal health survey. Ethnicity and Health, 2015, DOI:10.1080/13557858.2015.101 5499.
Disparities in Abortion Experience

17. Ganle JK, Parker M, Fitpatrick R, \& Otupiri E: Addressing Health System Barriers to Access to and Use of skilled delivery services: Perspectives from Ghana. International Journal of Health Planning and Management, 2015, DOI: 10.1002/ hpm.2291.

18. Ganle JK, Otupiri E, Parker M \& Fitpatrick R: Sociocultural barriers to accessibility and utilization of maternal and newborn healthcare services in Ghana after user-fee abolition. International Journal of Maternal and Child Health, 2015, 3(1): 1-14.

19. Ganle JK: Why Muslim women in northern Ghana do not use skilled maternal healthcare services at health facilities: A qualitative study. BMC International Health \& Human Rights, 2015, 15(10): DOI 10.1186/s12914-015-0048-9.

20. Ghana Statistical Services (GSS), Ghana Health Service (GHS), \& Macro International: Ghana Maternal Health Survey 2007. Calverton, Maryland, USA: GSS, GHS, and Macro International; 2009.

21. Ghana Statistical Service: Ghana Demographic \& Health Survey 2014. Accra: Ghana Statistical Service; 2014.

22. Lauro D: Abortion and Contraceptive Use in SubSaharan Africa: How Women Plan Their Families. African Journal of Reproductive Health, 2011, 15(1): 13-23.

23. Say L \& Raine R: A systematic review of inequalities in the use of maternal health care in developing countries: examining the scale of the problem and the importance of context. Bulletin of World Health Organization, 2007, 85:812-819.

24. Ahmed S, Creanga AA, Gillespie DG \& Tsui AO: Economic Status, education, and empowerment: implications for maternal health service utilization in developing countries. PLOS ONE, 2010, 5(6): e11190.

25. Asante AD \& Zwi AB: Factors influencing resource allocation decisions and equity in the health system of Ghana. Public Health, 2009, 123:371-377.

26. Osur J, Orago A, Mwanzo I \& Bukusi E: Social Networks and Decision Making for Clandestine Unsafe Abortions: Evidence from Kenya. African Journal of Reproductive Health, 2013, 19(1): 34-43.

27. Mundigo AI: Determinants of unsafe induced abortion in developing countries. In I.K. Warriner, I.H. Shah (eds). Preventing Unsafe Abortion and its Consequences: Priorities for Research and Action. New York:AGI, 2006, Pp.51-57. 